\title{
Thermal Water Applications in the Treatment of Upper Respiratory Tract Diseases: A Systematic Review and Meta-Analysis
}

\author{
Sarah Keller, Volker König, and Ralph Mösges \\ Institute of Medical Statistics, Informatics and Epidemiology (IMSIE), University Hospital of Cologne, 50924 Cologne, Germany \\ Correspondence should be addressed to Ralph Mösges; ralph@moesges.de
}

Received 28 February 2014; Accepted 23 April 2014; Published 1 June 2014

Academic Editor: Desiderio Passali

Copyright (C) 2014 Sarah Keller et al. This is an open access article distributed under the Creative Commons Attribution License, which permits unrestricted use, distribution, and reproduction in any medium, provided the original work is properly cited.

\begin{abstract}
Background. Thermal water inhalations and irrigations have a long tradition in the treatment of airway diseases. Currently there exists no systematic review or meta-analysis on the effectiveness of thermal water treatment in upper respiratory tract diseases. Methods. A systematic search in the databases of MEDLINE, EMBASE, CENTRAL, ISI Web of Science, and MedPilot was accomplished. Results. Eight evaluable outcome parameters from 13 prospective clinical studies were identified for 840 patients. Mucociliary clearance time improves significantly $(P<0.01)$ for the pooled thermal water subgroup and the sulphurous subgroup after 2 weeks ( $-6.69 /$ minutes) and after 90 days ( $-8.33 /$ minutes), not for isotonic sodium chloride solution (ISCS). Nasal resistance improved significantly after 2 weeks (Radon, ISCS, and placebo), after 30 days (sulphur and ISCS), and after 90 days (sulphur). Nasal flow improved significantly with the pooled thermal water, radon alone, and ISCS subgroups. For the IgE parameter only sulphurous thermal water $(P<0.01)$ and ISCS $(P>0.01)$ were analyzable. Adverse events of minor character were only reported for sulphurous treatment (19/370). Conclusion. Thermal water applications with radon or sulphur can be recommended as additional nonpharmacological treatment in upper airway diseases. Also in comparison to isotonic saline solution it shows significant improvements and should be investigated further.
\end{abstract}

\section{Introduction}

Upper airway diseases compass acute and chronic conditions. In this study, we focus on recurrent upper respiratory tract infections (RURT), allergic rhinitis (AR), nonallergic rhinitis (NAR), and acute and chronic rhinosinusitis (ARS/CRS) with and without nasal polyps. These disorders are extremely common and present in all ages, all ethnic populations, and all countries [1]. Apart from their high socioeconomic burden [2], "comorbidities are common and increase the complexity of the management and costs" [1].

Rhinitis is a symptomatic inflammation of the nasal mucosa including nasal symptoms like rhinorrhea, nasal obstruction, nasal itching, and sneezing [3]. The most common form of noninfectious rhinitis is AR with immunoglobulin E- (IgE-) mediated immune response after allergen exposure [1]. Nonallergic rhinitis shows periodic or perennial symptoms, which are not IgE-dependent such as infectious or vasomotor rhinitis [4]. Infectious rhinitis has either viral, bacterial, or other infectious agents origin [3] and affects millions of people annually [5].

Rhinitis and sinusitis mostly coexist and have been proposed as rhinosinusitis [6]. The European Position Paper on Rhinosinusitis and Polyps EPOS 2012 [7] defines rhinosinusitis as an inflammation of the nose and paranasal sinuses characterised by two or more symptoms, one of which should be either nasal blockage/obstruction/congestion or nasal discharge. Further, either endoscopic or CT proof is obligatory. Acute and chronic rhinosinusitis are distinguished in length of illness and grade of decay of symptoms. It is characterised by a duration of more than 12 weeks without complete resolution of symptoms and affects approximately $5-15 \%$ of the general population [7-9].

State-of-the-art documents ARIA [3] and EPOS [7] provide evidence-based treatment guidelines where "antiinflammatory medication represents the first-line treatment" 
[10]. Along with steroid/pharmacological treatment, EPOS [7] recommends nasal saline irrigation as additional firstline treatment in acute and chronic rhinosinusitis and after sinonasal surgery [7]. Some reviews also state nasal irrigation as adjunctive treatment for allergic rhinitis, acute upper respiratory tract infections, and rhinitis of pregnancy [1113]. Data for nasal inhalation is limited; EPOS [7] mentions inhalation treatment only in acute rhinosinusitis without evidence. Other guidelines from the German Society of Otorhinolaryngology have an open suggestion for inhalation in rhinosinusitis for symptomatic relief [14].

The current treatment regimens for CRS and AR are effective in the majority of patients, but there are a number of patients still suffering from symptoms [10]. Especially under chronic conditions with long-term drug consumption like glucocorticosteroids, many patients hesitate to take medicine. A publication by Kaschke points out that $64 \%$ of AR patients have steroid phobia [15]. It is observed that more and more patients inquire about nonpharmacological therapy approaches in the treatment of rhinosinusitis [16]. Possible approaches besides the proven saline irrigation could be the use of thermal water irrigations and inhalations.

Concerning medical spending, a study by Bhattacharyya points out that the annual costs for medication to treat CRS with intranasal steroids, nonsedating antihistamines, and antibiotic therapy were $\$ 213, \$ 227$, and $\$ 335$ in 2003 [2]. Averaging the annual cost of sinus medications including overthe-counter remedies, nasal steroid sprays, and antibiotics, the calculations of Gliklich and Metson result in $\$ 1220$ per patient [17].

In the United States the medical spending for AR almost doubled from $\$ 6.1$ billion in 2000 to $\$ 11.2$ billion in 2005 [18]. Nasal saline irrigation in AR patients helps to reduce medicine consumption by an average of $2.99 \%$ [19]. Thermal water applications present an inexpensive nonpharmacological adjunction as well and could therefore further reduce the medicine consumption and costs.

Thermal water treatment belongs to Balneology. Balneology (lat. balneum: bath) is the science of natural curative waters, curative gases, and peloides and their use in the treatment of diseases not only as baths, inhalations, or irrigations but also as drinking cures or mud packs [20]. Thermal inhalations and irrigations are century-old practices and already the Romans appreciated the health-promoting effects of different thermal sources.

According to German regulations, natural curative waters are characterised by a minimum content of $1 \mathrm{~g}$ dissolved minerals per liter. The designation "thermal water" requires a temperature of a minimum of $20^{\circ} \mathrm{C}$ when emerging from the spring [21]. Among the many different types of thermal waters our focus is on sulphurous and radon waters. Sulphurous water and its therapeutical use belong to the oldest forms of balneology. It is said to break disulphide bonds of the mucin and activate breathing and blood circulation and helps to reduce inflammation [20,22, 23]. Radon is a radioactive gas which emits alpha rays. Its very low content in thermal sources has biopositive effects which stimulate cellular activity [24].
Several studies show significant results in thermal water treatment with inhalation or irrigation treatment [25-29]. Up to now no systematic review or meta-analysis on thermal water application in upper airway diseases exists.

\section{Materials and Methods}

A comprehensive search in the databases of MEDLINE (Medical Literature Analysis and Retrieval System Online), CENTRAL (Cochrane Central Register of Controlled Trials), EMBASE (Excerpta Medica Database), Web of Science, and MedPilot was conducted. In the systematic search the terms "thermal water," "Spa therapy," "thermal water inhalations," and "Spa treatment" were combined with the terms "rhinitis," "rhinosinusitis," "allergic rhinitis," "chronic rhinitis," and "nasal irrigation" with the Boolean operator "and" in all fields. Furthermore, the terms "Radon Spa therapy," "Balneotherapy," "Sulphurous Water," "Bromide Water," "Iodic Water," "Salty Water," and "Radon Water" were linked through "and" with "rhinitis" or "rhinosinusitis." No limitation was made in language, publication date, and duration of the study or the demographic data of patients. Literature published up to and including 27 February 2014 was included.

The inclusion criteria for this meta-analysis were as follows: clinical studies conducted with thermal water for the upper airway diseases, allergic, chronic, or acute rhinosinusitis, at least three or more points on the modified JADAD scale [30], and the presence of the complete statistical data sets consisting of mean deviation, standard deviation, and sample size (if appropriate, calculation using standard error or the upper and lower quartile) at defined follow-up time points.

The following outcome parameters were examined in this study: the mucociliary clearance time (MCT), nasal respiratory flow (Flow), nasal resistance (R), immunoglobulin values $\mathrm{A}, \mathrm{E}, \mathrm{G}$, and $\mathrm{M}$, and adverse events (AE).

\section{Data Collection and Analysis}

The search described above initially resulted in 2113 matches. Duplicates and studies that were either nonclinical or diseasespecific not relevant for this analysis were excluded so that the abstracts of 50 remaining studies were examined. Another 15 could be excluded after the perusal of the abstract. 35 studies were investigated in full-text which led to the exclusion of another seven studies due to divergent treatment modalities [22, 31, 32], mismatching disease patterns [33, 34], unavailability [35], or the conduction of the study with animals [36].

The remaining 28 articles were evaluated by two independent reviewers with the modified Jadad Scale by Oremus et al. [30]. It amplifies the original 3-item Jadad Scale [37] consisting of randomization, blinding, and study dropouts by adding inclusion/exclusion criteria, side effects, and statistical methods. Additionally, it features two bonus points for appropriate randomisation method and double-blinding. If this does not apply, these points are deducted. The minimum score is 0 points; the maximum score is 8 points. 
We set a minimal score of at least three points to establish a qualitative homogeneity essential for our meta-analysis. Thus another 15 studies were excluded [38-52] and 13 studies remained for our analysis. Four of those are in Italian and nine in English.

The different thermal waters used in the studies included were pooled concerning their different substances. This resulted in two main groups: sulphurous water with nine studies $[25-28,53-57]$ and radon water with two studies $[29,58]$. Salt-bromine-iodine water [59] and hypermineral chloride sodium water [60] were used once. We also pooled a common thermal water group to compare it to isotonic sodium chloride solution (ISCS) and placebo. Figure 1 shows a flowchart of the literature identification process. Tables 1 and 2 show the included studies in a systemic overview.

3.1. Statistical Methods. The statistical calculations were performed using the statistic software Comprehensive MetaAnalysis Version 2.2.064 (Biostat, Inc.). The study values for the identified outcome parameters were sorted according to the time of measurement (baseline, 12 days, 2 weeks, 30 days, and 90 days). Studies with the same parameter and different (follow-up) times of measurement, of 12 and 14 days, were combined to one-time measurement (2 weeks). All points of measurements of the different studies were summarised and analysed using the random-effect model. The mean and, respectively, the standard error of the mean are depicted in the figures (Figures 2-5). In the following analysis we assumed a significance if the $P$ value was less than or equal to $5 \%(P \leq 0.05)$. For clarification, significant improvements/changes are marked with ${ }^{*}$ in Tables $4-7$. For some identified parameters data were available from one study only and therefore had to be excluded from the metaanalysis but are, for the sake of completeness, included in the figures with an interrupted line.

\section{Results}

In total, 13 studies published between 1998 and 2013 have been included in this analysis.

All forms of applications were pooled. The specific form of application and the number of patients is depicted in Table 3. An aerosol therapy is categorised under inhalations. Altogether, 430 patients received irrigations and 557 patients inhalations.

4.1. Study Design. All studies feature a prospective study design. Five studies are randomised, controlled, and doubleblind [25-28, 54]; other three studies are randomised and controlled [56, 59, 60]; one study is controlled and doubleblind [29]; one is only double-blind [55]. The remaining studies are not randomised, blinded, or controlled $[53,57,58]$. ISCS was used for the control groups, drinking water or distilled water for placebo groups. The duration of the studies varies between 12 days and 6 months.

4.2. Selection of Patients. A total number of 840 patients aged between 2 and 100 years took part in these studies, 510 of them received an application with thermal water, 285 were treated with ISCS [25-28, 56, 59], 20 inhaled drinking water [29], and 25 inhaled distilled water [54].

4.3. Mucociliary Clearance Time. MCT was examined in seven studies with 422 patients in total (Table 4). Thermal water (radon, sulphur, and salt-bromine-iodine) applications showed a significant improvement of MCT compared to baseline at both points of measurement (Figure 2). The measurement for ISCS compared to baseline showed no significance after two weeks but after 90 days in the followup. Only one study was conducted with placebo which did not show any significance neither did radon water applications $(P=0.059)$. Sulphurous water applications showed significant lower values after two weeks compared to the baseline value $(P<0.01)$ and are also significant lower after 90 days compared to the baseline values $(P<0.01)$.

In an internal comparison between the ISCS group and the sulphurous water group we had nonsignificant initial situations $(P=0.211)$, but after 2 weeks and 90 days the outcome differed significantly $(P<0.01)$. The ISCS and the radon group already differed significantly in baseline values $(P<0.05)$ and had almost parallel curves.

Figure 2 illustrates all values calculated in the metaanalysis and noted in Table 4 .

4.4. Nasal Resistance. Nasal resistance was measured in six of the included trials with a total number of 347 patients (Table 5). Thermal water treatment was not significant after two weeks but after 30 and 90 days compared to baseline. ISCS treatment showed significance after two weeks and 30 days compared to baseline, but after 90 days there was no significance. This graph (Figure 3, ISCS graph) showed a very erratic curve due to the very heterogeneous study design and the different points of measurement of the three studies included. Both the treatment with placebo and the treatment with radon water showed significance after two weeks. The treatment with sulphurous water showed significance after 30 $(P<0.01)$ and 90 days $(P<0.05)$ but not after two weeks $(P=0.118)$.

4.5. Nasal Flow. The nasal flow was specified in three of the included trials with 117 patients (Table 6). All of these patients received inhalation and aerosol therapy. Figure 4 shows all included studies, using this outcome parameter, the dotted lines for placebo and sulphur indicate single studies. Compared to baseline, the combined thermal water group $(P<0.05)$, as well as the radon $(P<0.05)$ and the sulphurous water group $(P<0.01)$, showed significant improvement after two weeks, whereas drinking water application $(P=$ 0.425 ) showed no improvement or significance.

4.6. Immunoglobulins $E, A, G$, and $M$. Immunoglobulin concentrations in the blood were examined in two of the included trials $[25,26]$ with a total number of 180 patients. Both studies compared sulphurous water treatment to ISCS treatment. Distribution of the number of patients ( 90 patients per group) was equal in both studies. 

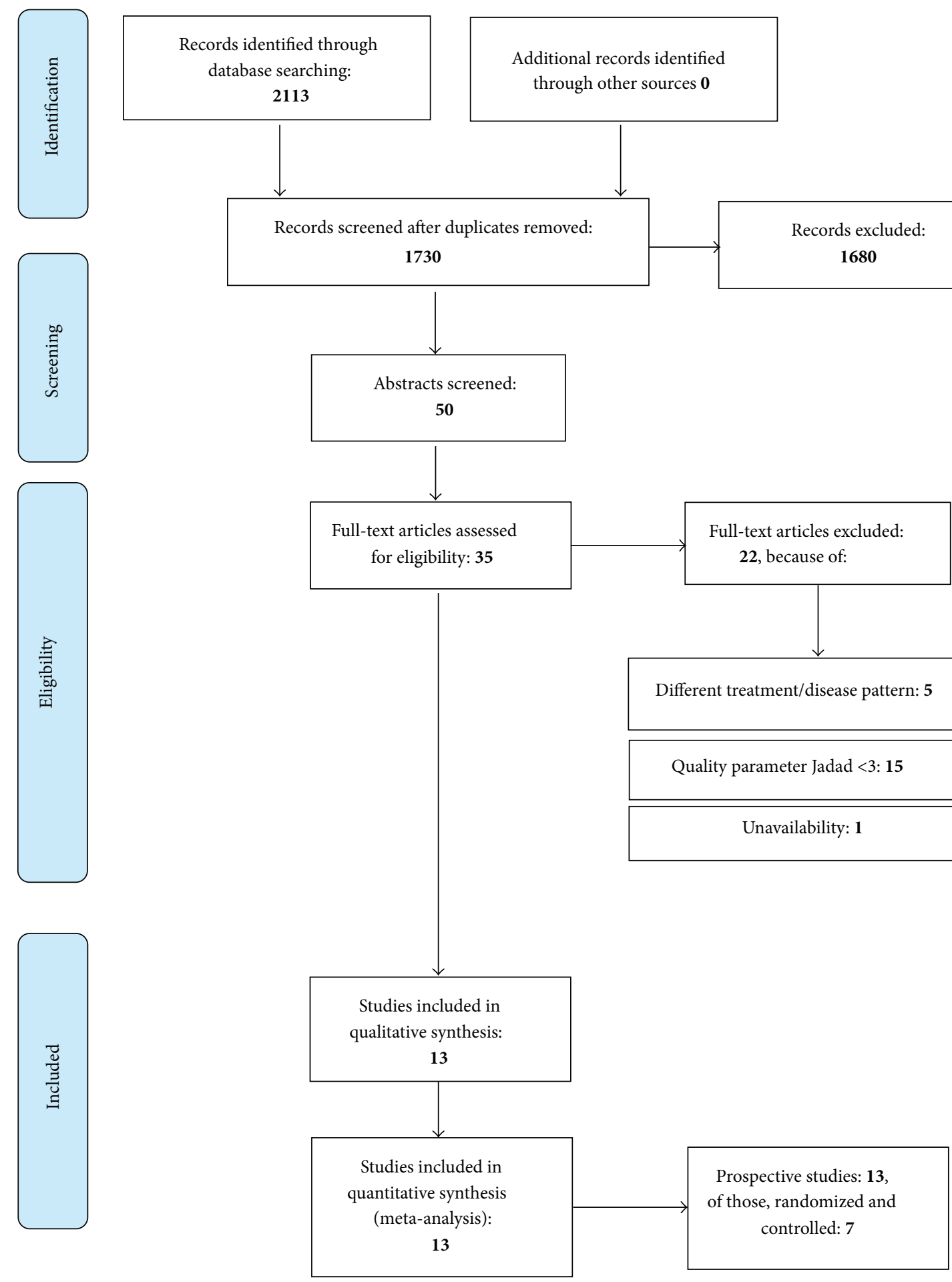

FIgURE 1: Flow chart. Source: PRISMA 2009 Flow chart [61], augmented with exclusions and types of included studies.

4.7. IgE. Figure 5 illustrates the meta-analysis outcome for IgE. Both groups started from a comparable initial position. Sulphurous water treatment rose significantly $(P<0.01)$ at both measurement points 12 and 90 days compared to baseline in contrast to ISCS treatment which was neither
Additional records identified through other sources $\mathbf{0}$

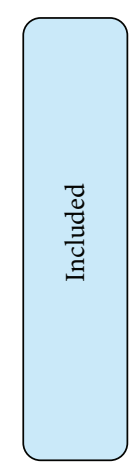

Prospective studies: 13, of those, randomized and controlled: 7 


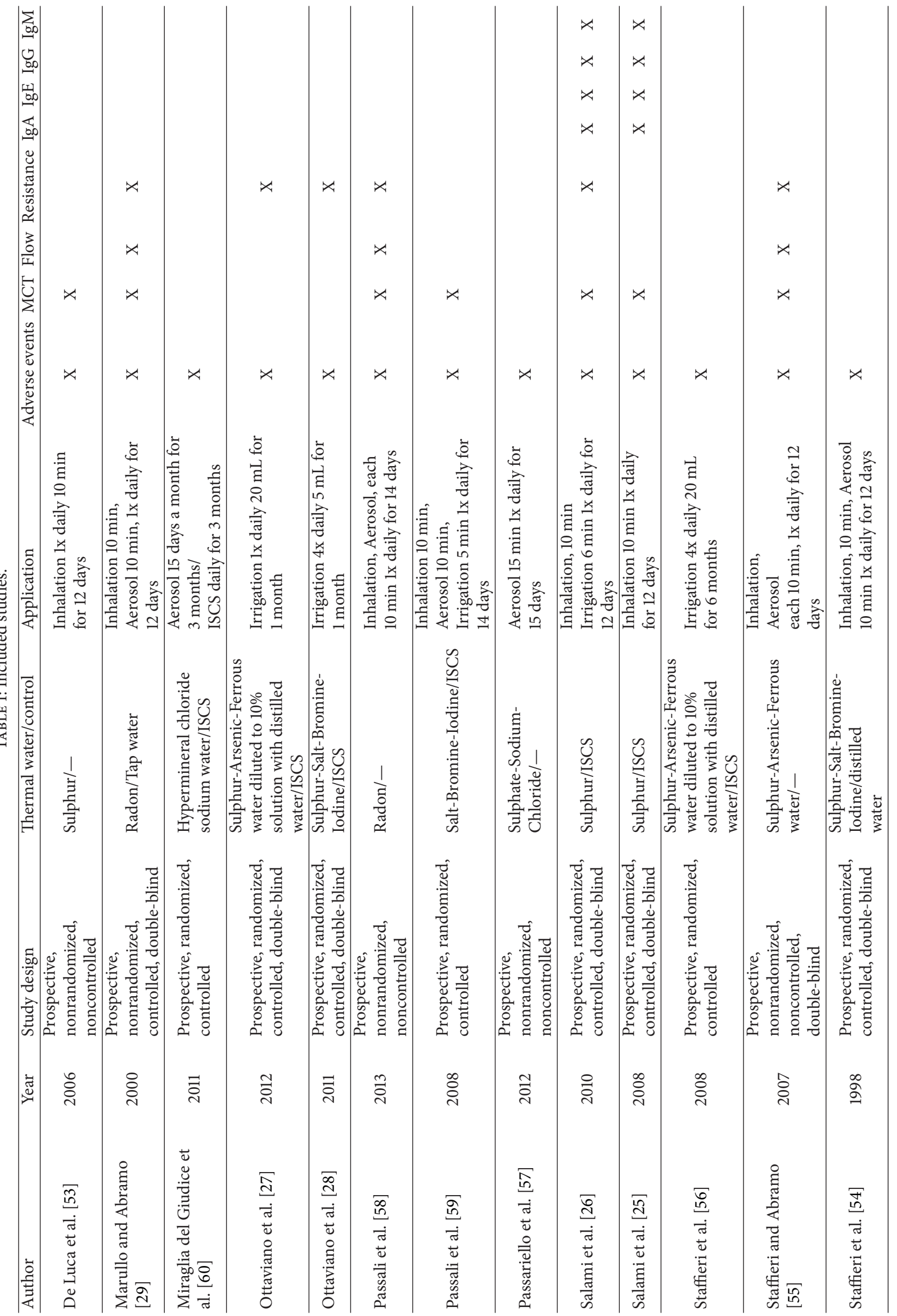




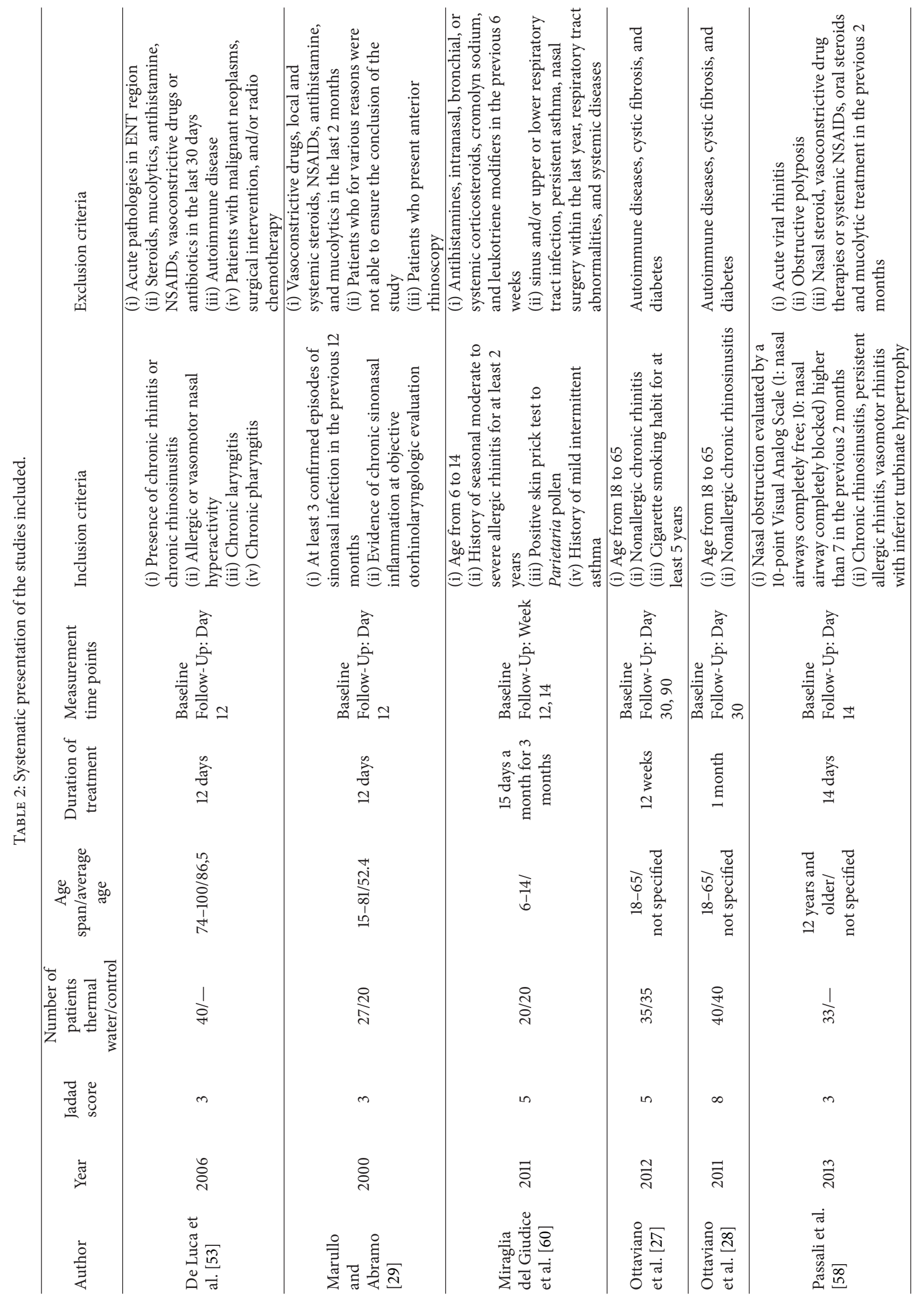




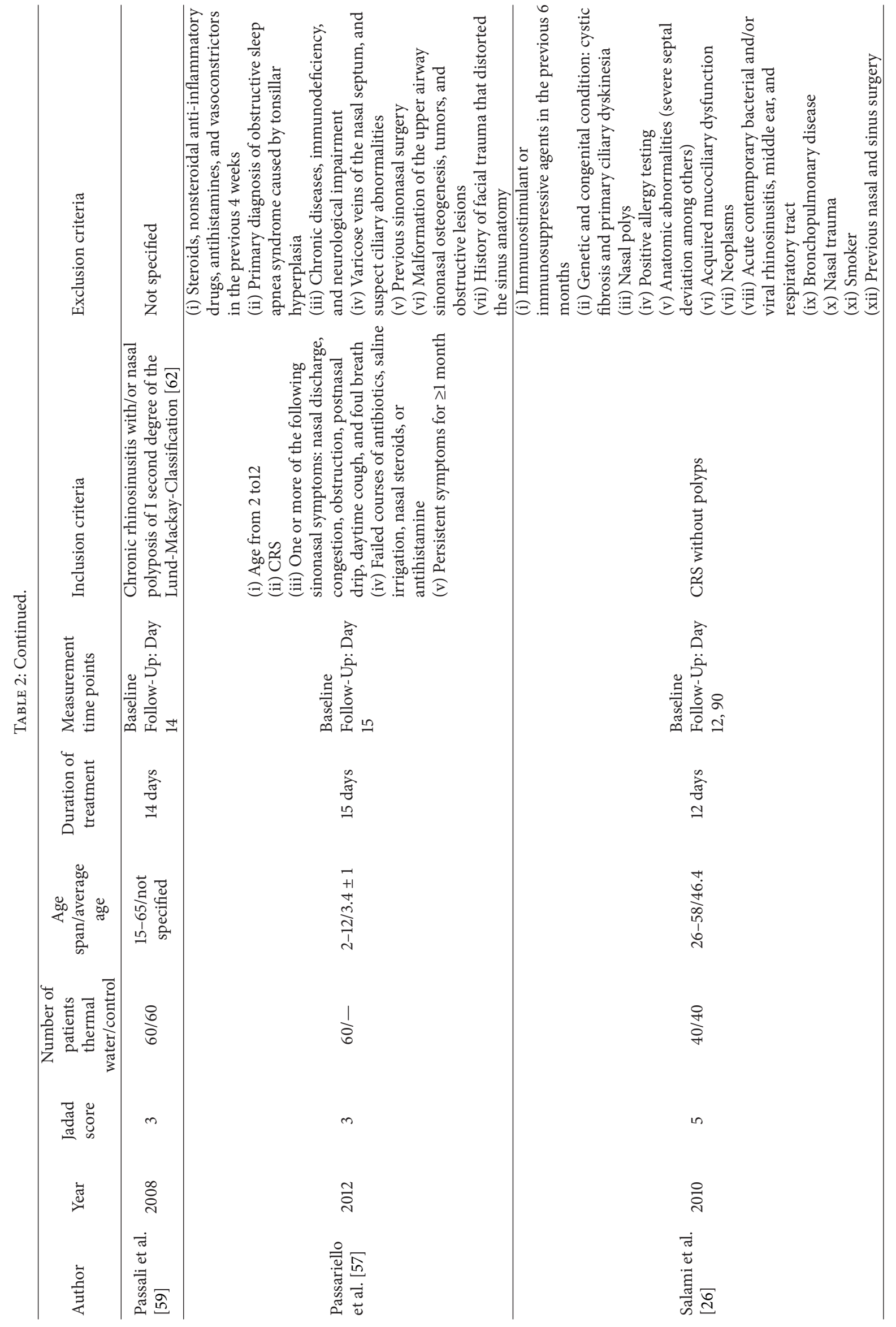




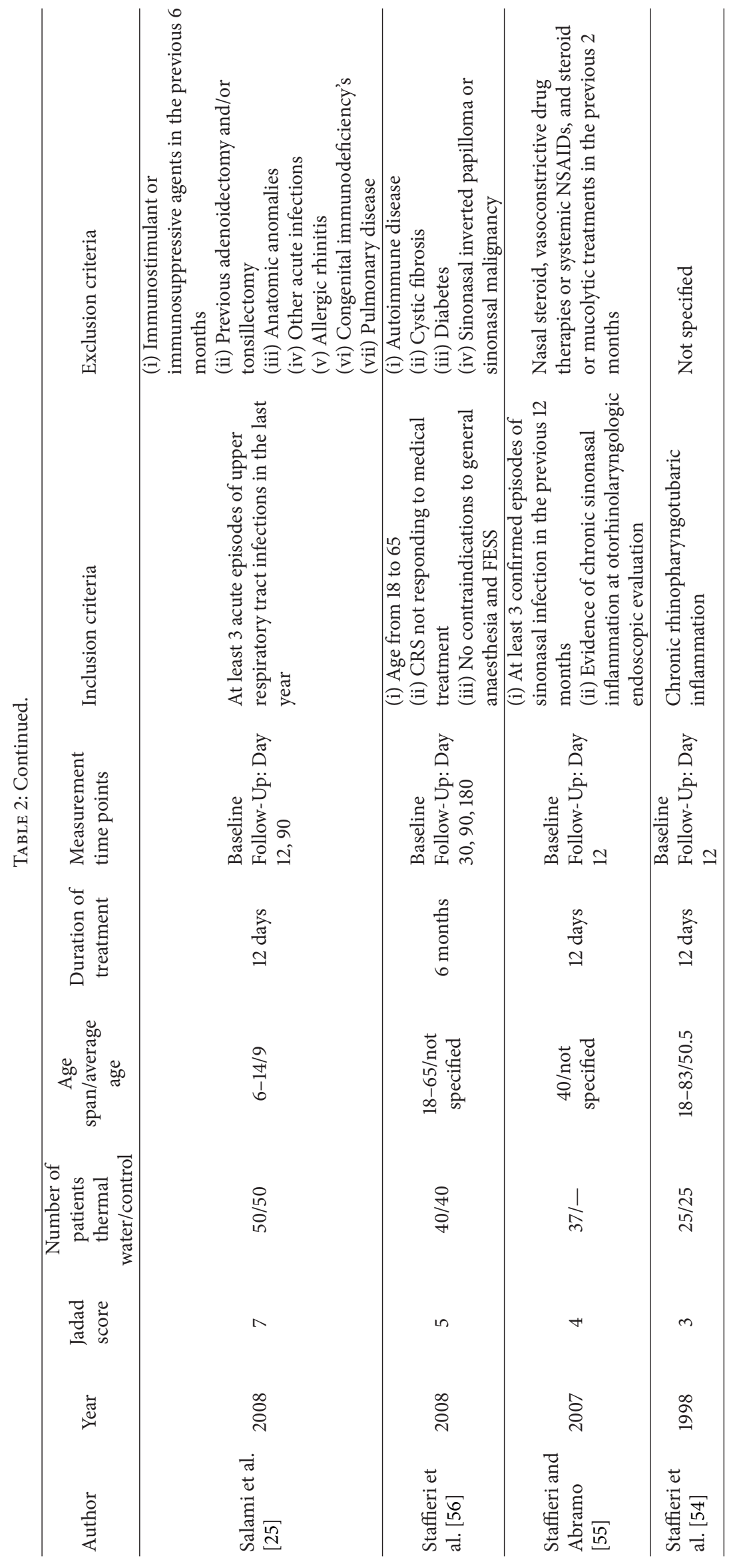




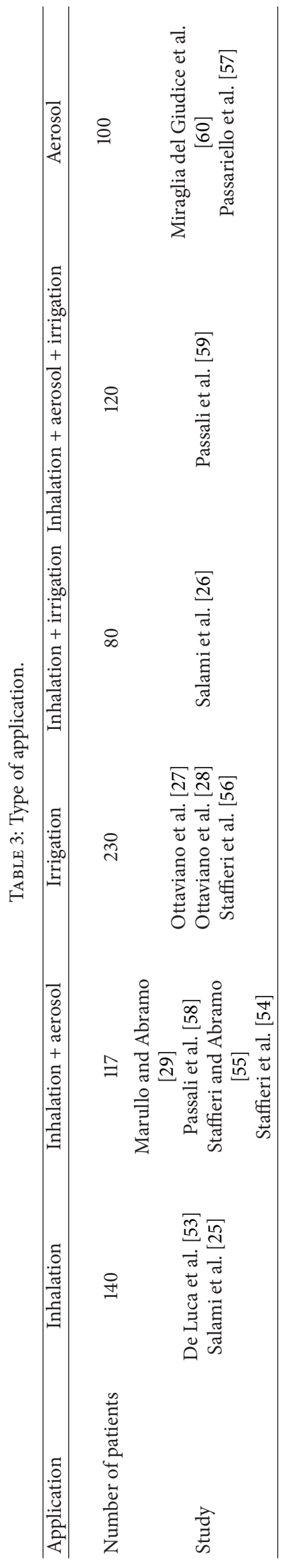




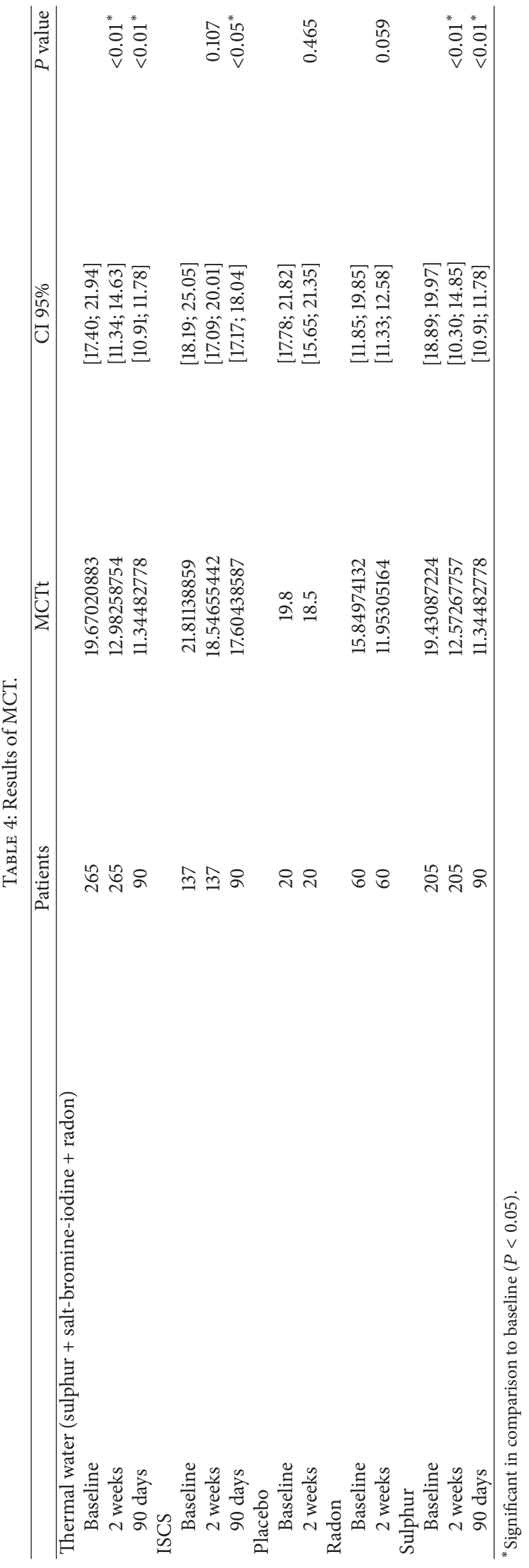


TABLE 5: Results of nasal resistance.

\begin{tabular}{|c|c|c|c|c|}
\hline & Patients & NasRes & CI $95 \%$ & $P$ value \\
\hline \multicolumn{5}{|c|}{ Thermal (sulphur + radon) } \\
\hline Baseline & 212 & 0,442260114 & {$[0.26 ; 0.62]$} & \\
\hline 2 weeks & 137 & 0.257467503 & {$[0.22 ; 0.30]$} & 0.051 \\
\hline 30 days & 66 & 0.113901251 & {$[0.05 ; 0.18]$} & $<0.01^{*}$ \\
\hline 90 days & 64 & 0.159927083 & {$[0.003 ; 0.32]$} & $<0.05^{*}$ \\
\hline \multicolumn{5}{|l|}{ ISCS } \\
\hline Baseline & 115 & 0.516633 & {$[0.13 ; 0.90]$} & \\
\hline 2 weeks & 40 & 1.28 & {$[1.16 ; 1.40]$} & $<0.01$ \\
\hline 30 days & 62 & 0.124408602 & {$[0.10 ; 0.15]$} & $<0.05$ \\
\hline 90 days & 68 & 0.617283393 & {$[-0.36 ; 1.60]$} & 0.851 \\
\hline \multicolumn{5}{|l|}{ Placebo } \\
\hline Baseline & 20 & 0.23 & {$[0.19 ; 0.27]$} & \\
\hline 2 weeks & 20 & 0.19 & {$[0.17 ; 0.21]$} & $<0.05^{*}$ \\
\hline \multicolumn{5}{|l|}{ Radon } \\
\hline Baseline & 60 & 0.364606147 & {$[0.33 ; 0.40]$} & \\
\hline 2 weeks & 60 & 0.240700629 & {$[0.15 ; 0.33]$} & $<0.05^{*}$ \\
\hline \multicolumn{5}{|l|}{ Sulphur } \\
\hline Baseline & 152 & 0.495021367 & {$[0.22 ; 0.77]$} & \\
\hline 2 weeks & 77 & 0.272182942 & {$[0.26 ; 0.29]$} & 0.118 \\
\hline 30 days & 66 & 0.113901251 & {$[0.05 ; 0.18]$} & $<0.01^{*}$ \\
\hline 90 days & 64 & 0.159927083 & {$[0.003 ; 0.32]$} & $<0.05^{*}$ \\
\hline
\end{tabular}

${ }^{*}$ Significant in comparison to baseline $(P<0.05)$.

TABLE 6: Results of nasal flow.

\begin{tabular}{|c|c|c|c|c|}
\hline & Patients & NasFlow & CI 95\% & $P$ value \\
\hline \multicolumn{5}{|c|}{ Thermal (sulphur + radon) } \\
\hline Baseline & 97 & 604.1 & {$[513.68 ; 694.45]$} & \\
\hline 12-14 days & 97 & 721.5 & {$[697.18 ; 745.84)$} & $<0.05^{*}$ \\
\hline \multicolumn{5}{|l|}{ Placebo } \\
\hline Baseline & 20 & 714.3 & {$[664.13 ; 764.47]$} & \\
\hline 12-14 days & 20 & 687.5 & {$[644.79 ; 730.21]$} & 0.425 \\
\hline \multicolumn{5}{|l|}{ Radon } \\
\hline Baseline & 60 & 633.4 & {$[540.95 ; 725.90]$} & \\
\hline 12-14 days & 60 & 738.8 & {$[703.64 ; 773.89]$} & $<0.05^{*}$ \\
\hline \multicolumn{5}{|l|}{ Sulphur } \\
\hline Baseline & 37 & 558.4 & {$[526.53 ; 590.27]$} & \\
\hline 12-14 days & 37 & 705.6 & {$[671.86 ; 739.34]$} & $<0.01^{*}$ \\
\hline
\end{tabular}

${ }^{*}$ Significant in comparison to baseline $(P<0.05)$.

and $\mathrm{M}$, neither beyond the subgroups between ISCS and sulphur nor in the individual groups between the baseline and the maximal treatment duration of 90 days.

4.9. Adverse Events. All adverse events that occurred during the studies in the entire patient population were extracted and illustrated in forest plots. In total, 19 patients out of 840 treated patients suffered from study related adverse events.
All adverse events occurred under the treatment with sulphurous water: 13 patients experienced mild nasal irritation and a sensation of burning after application and five suffered from very limited epistaxis, one from an aggravation of the symptoms, and one from dermatological hypersensitivity. No adverse events are reported for the treatment with another thermal water, ISCS, or placebo.

For sulphurous water, 19 adverse events occurred in a total group of 370 patients. This led to an adverse event rate of 
TABLE 7: Results of IgE.

\begin{tabular}{lcccc}
\hline & Patients & $\operatorname{IgE}$ & CI 95\% & $P$ value \\
\hline Sulphur & & & & \\
Baseline & 90 & 105.11 & {$[98.53 ; 111.69]$} & $<0.01^{*}$ \\
12 days & 90 & 75.65 & {$[70.13 ; 81.18]$} & $<0.01^{*}$ \\
90 days & 90 & 74.79 & {$[69.38 ; 80.19]$} & \\
ISCS & & & & {$[94.03 ; 109.35]$} \\
Baseline & 90 & 101.69 & {$[88.22 ; 105.98]$} & 0.442 \\
12 days & 90 & 97.10 & {$[89.60 ; 107.00]$} & 0.567 \\
90 days & 90 & 98.30 & & \\
\hline
\end{tabular}

${ }^{*}$ Significant in comparison to baseline $(P<0.05)$.

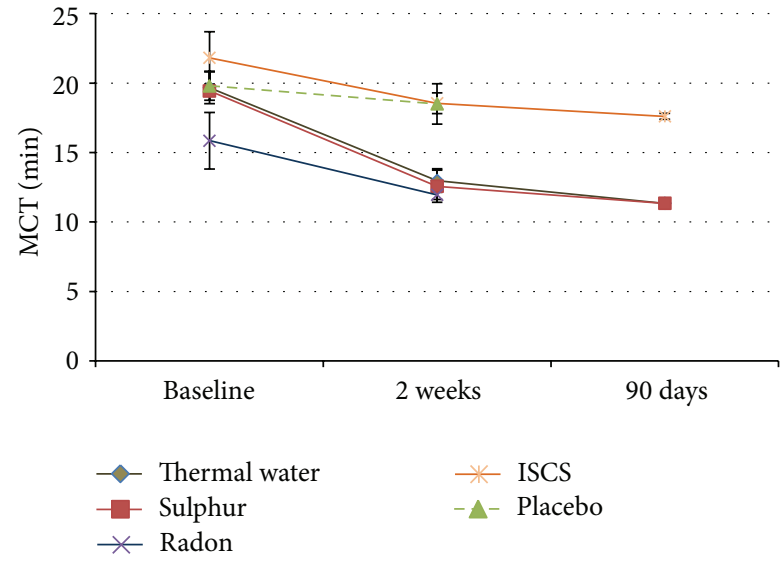

FIGURE 2: Mucociliary clearance time.

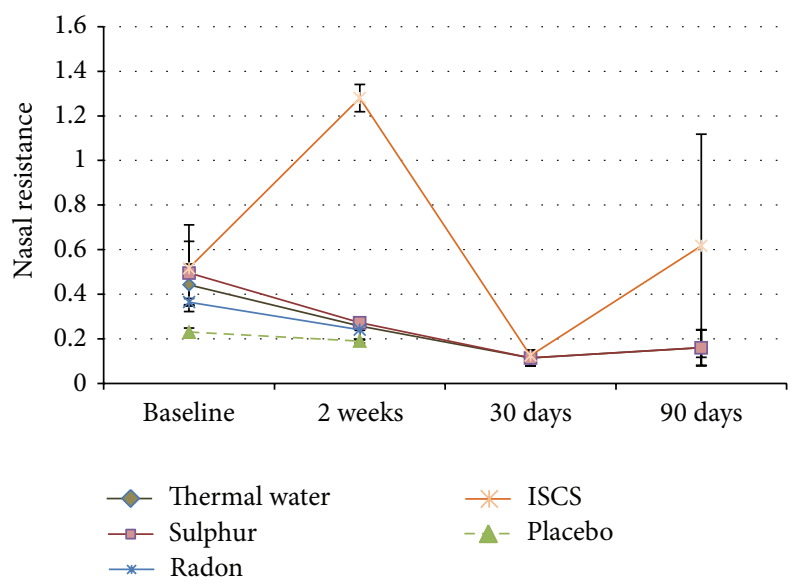

FIgURE 3: Nasal resistance.

$11.9 \%$. The assumed rate of adverse events ranged from 7.8 to 17.6\% (Figure 6).

By pooling all thermal water subgroups we received a total number of 510 treated patients with 19 adverse events. This led to an adverse event rate of $9.8 \%$ with an assumed range from 6.6 to $14.4 \%$ (Figure 7 ).

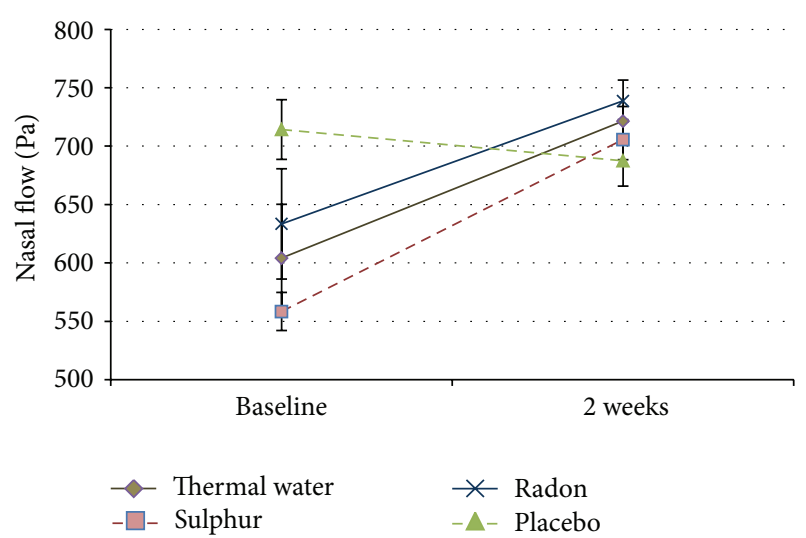

FIgURE 4: Nasal flow. Dotted lines present single studies.

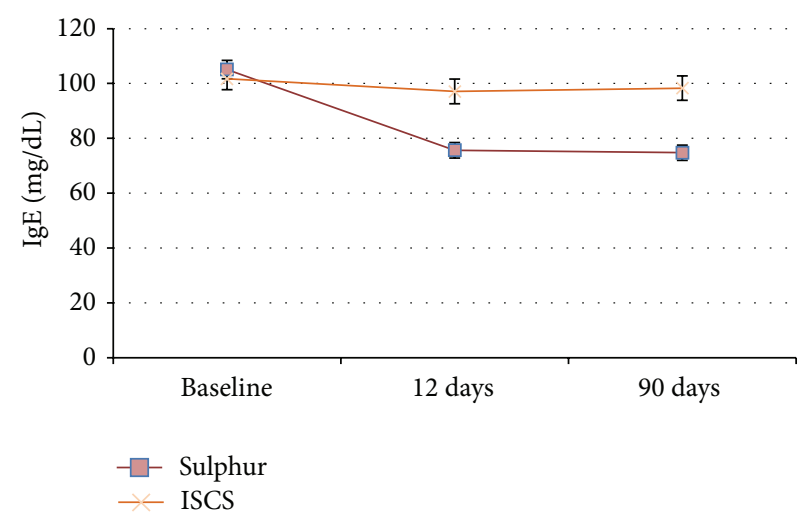

Figure 5: IgE in serum.

\section{Discussion}

This review and its appertaining meta-analysis is the first systematic approach to thermal water treatment in upper respiratory tract diseases. For the identified outcome parameters some significant improvements could be found in the treatment with thermal water irrigation and inhalation.

In order to ensure methodological quality of the included trials, two independent reviewers applied the modified Jadad Scale to every study with a minimal score of 3 . 


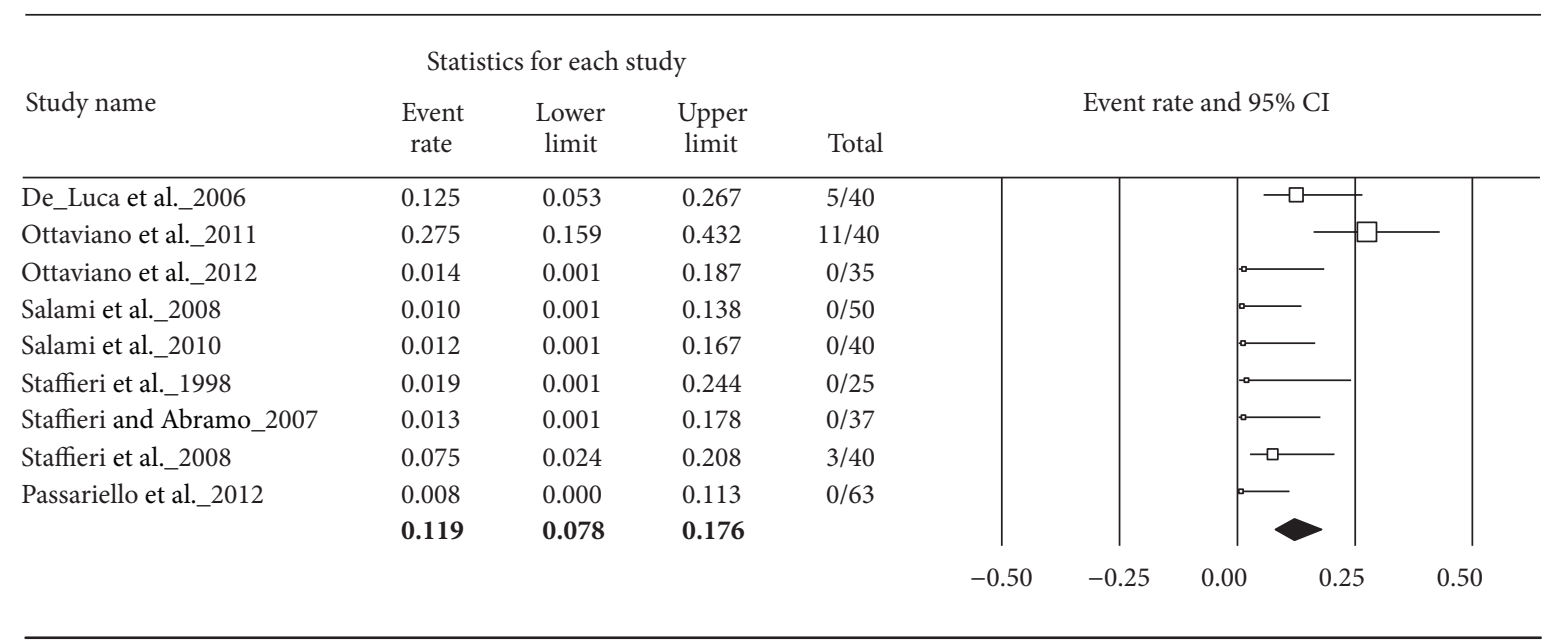

FIGURE 6: Adverse events for sulphurous water.

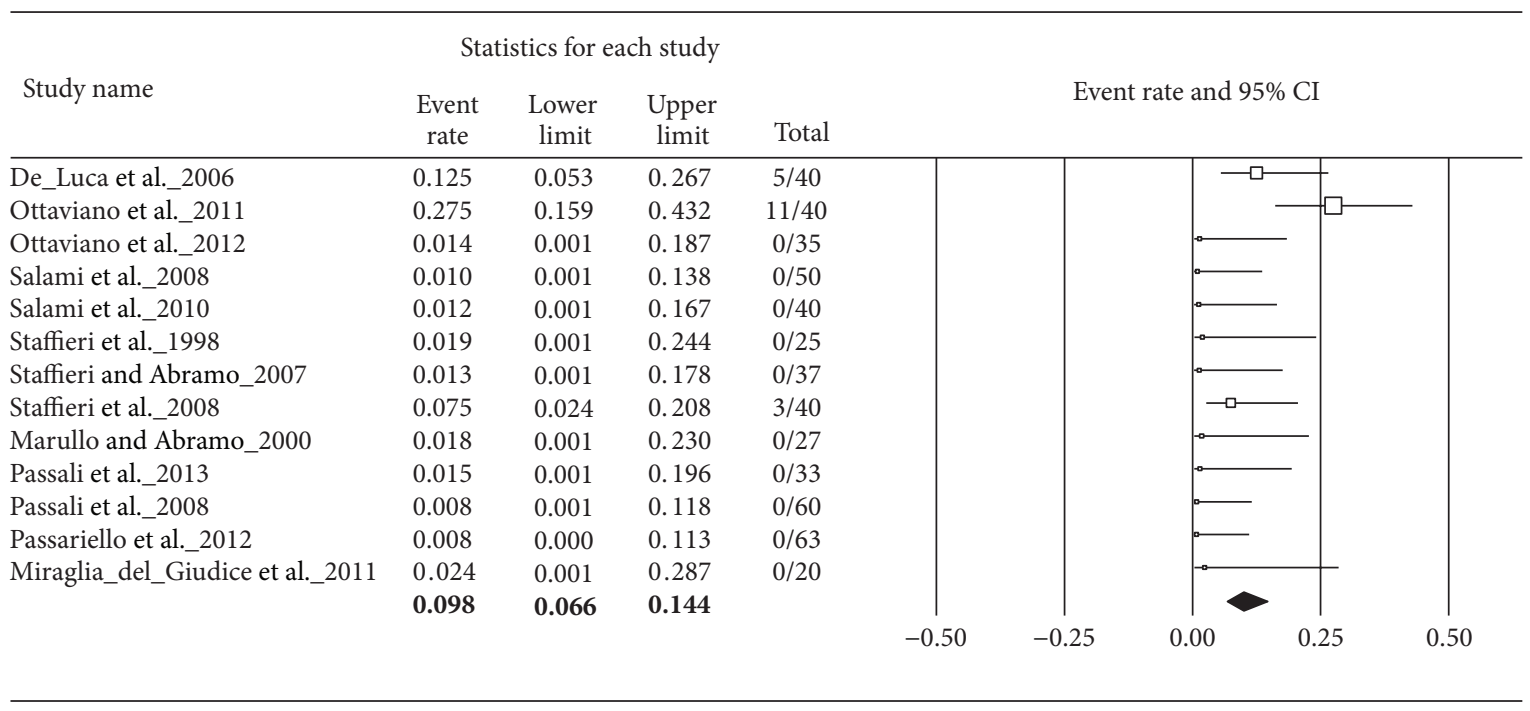

FIGURE 7: Adverse events for thermal water.

Further this meta-analysis is calculated by the "random effects" model, which takes possible heterogeneity more into consideration than the "fixed effect" model. The confidence intervals are broader and thus capture the true value of the meta-analysis. Where relative overestimation of smaller studies can result in greater inaccuracy, this is a more conservative and cautious estimation. It constitutes a higher risk for bias of the results [63].

In addition, we pooled the clinical pictures of allergic, acute, and chronic rhinosinusitis as well as studies with children, adults, and elderly people. In two studies patients with minimally invasive functional endoscopic sinus surgery (FESS) before treatment were included. This can be assumed as selection bias for this meta-analysis. Furthermore, only published studies were included in this meta-analysis. Thus, publication bias may occur.

Besides irrigation, also inhalation therapy was used in the different studies. Both treatments reduced inflammatory mediators in nasal secretions [64]. Nasal irrigation had a direct physical cleansing effect by flushing out thick mucus, crusts, debris, allergens, and air pollutants [65]. In a review by Hermelingmeier et al. the conclusion drawn is that there is no clear data available naming the most advantageous form of application in nasal saline irrigation [19].

The present meta-analysis shows a significant advantage of mucociliary clearance changes with thermal water in comparison to isotonic saline solution. This leads to a more detailed view of the results of thermal water applications found in this meta-analysis.

The MCT parameter comprises the best set of data in our meta-analysis with seven included studies and 422 patients. Mucociliary clearance is an important defence mechanism for both upper and lower airways and "its impairment[...] predisposes to chronic infection of the nose, paranasal sinuses and the respiratory tree" [66]. The average MCT values range below 15 minutes with a test duration of less than 
1 hour [67]. In this meta-analysis a significant improvement of the mucociliary clearance could be determined in thermal water applications. Hereby, the transport time could be reduced from 19.67 minutes initially to 12.98 minutes after two weeks and to 11.34 minutes after 90 days. Especially the application of sulphurous water showed a high significance $(P<0.001)$ after the two-week treatment period. At the same time the treatment with radon thermal water $(P=0.059)$ only just lacked a significant improvement $(P=0.059)$.

The literature available for these two subgroups was $5: 2$ with only 60 patients in the radon group which might have had an influence on the significance. In contrast to the thermal water group, the ISCS group only showed significance after 90 days of treatment. In turn the literature available was quite strong with 4 studies and a total of 205 patients.

Based on Marullo's study only it was not possible to conduct a meta-analysis and draw a valid conclusion on the use of placebo [29]. The meta-analysis of the mucociliary clearance time showed a significant benefit especially of the pooled thermal water treatment and sulphurous water over ISCS.

The "nasal resistance is the resistance offered by the nasal cavity to inspired air" [68] and it is measured in Pascal (Pa). All studies used for this analysis already resulted in significant changes after two weeks of treatment with radon thermal water. ISCS differed significantly after two weeks and after 30 days of treatment. The meta-analysis revealed significant variations in the three pooled ISCS studies. Especially the study of Salami et al. displayed a high deviation from the baseline of $13.1 \mathrm{~Pa}$, which was reduced to $1.28 \mathrm{~Pa}$ after two weeks and remained rather high after 90 days of treatment with 1.12 Pa.

Opposed to these findings were those of the two other studies of this pool $[27,28]$, which began with much lower baseline values of 0.14 and $0.17 \mathrm{~Pa}$ and had different followups. Therefore these led to an unsteady curve and limited the possibility of a serious interpretation of the healing process. Nevertheless, each of these three studies showed a reduction of the nasal resistance.

The treatment with sulphurous water showed good results throughout the whole treatment period of 90 days. The results were even better after 30 and 90 days than at the beginning, which allows for the assumption that a more permanent improvement is gained here.

Based on this meta-analysis we can assume that radon water application shows significant improvement in nasal flow. The data is quite limited with the results of only one study for placebo and one for sulphurous treatment, so that we cannot compare it to the pooled results.

The use of radon thermal water as well as the entire thermal water subgroup showed a significant improvement in the nasal flow after two weeks of treatment.

In our meta-analysis of IgE, sulphurous water treatment was highly significant after 12 and 90 days. ISCS treatment showed no significance. The present IgE results were measured in patients with chronic inflammatory conditions, where eosinophil cells in the mucus are increased [69]. Reduction of eosinophil cells after thermal water treatment was also reported in Passali et al. [58] and significantly decreased in Staffieri and Abramo [55]. Hypereosinophilia is related to high levels of serum concentrations of $\operatorname{IgE}[26,70]$. The IgE concentration which decreased significantly after the application with sulphurous water confirmed beneficial effects on chronic inflammatory disorders. Sulphurous water helps to clean the nasal mucosa from irritations and reduces immune responses at a local level $[25,71]$. These results support the assumption that sulphurous water has an antiinflammatory effect.

IgA, IgG, and IgM values in the blood did not increase significantly neither with sulphurous water nor with ISCS. Unfortunately the literature available on the secretory $\operatorname{IgA}$, which is secreted across the mucosa and plays a significant role in specific immune defence by preventing or blocking the adhesion of bacteria and defending the mucous membranes from common infection $[72,73]$, was not sufficient for a statistical analysis. Similarly, comparable studies investigating the IgM and IgG in the mucosa were missing.

Generally speaking, thermal water application is a safe treatment. Adverse events occurred in 19 out of 510 thermal water treatments and mainly consisted of mild nasal irritation, a sensation of local burning after application, and very limited epistaxis. All of these adverse events occurred under the treatment with sulphurous water. Neither for radon water, ISCS, nor placebo treatment adverse events were reported. It should be noted that both the studies by Staffieri et al. [56] and Ottaviano et al. [28] were conducted in a postoperative setting, which makes the occurrence of such adverse events more likely. Further, the study by De Luca et al. [53] was conducted with elderly people between 72 and 100 years.

\section{Conclusion}

Nasal application of thermal water results in a significant improvement of MCT, nasal flow, nasal resistance, and IgE concentration. The systematic review and the meta-analysis demonstrate an advantage of thermal water treatment over isotonic saline solution and placebo. Even though this aspect needs to be investigated further with randomised controlled trials in bigger cohorts and longer follow-up periods, it was shown that the application with thermal water can serve as additional nonpharmacological alternative.

\section{Abbreviations}

AE: Adverse events

AR: Allergic rhinitis

ARIA: Allergic rhinitis and its impact on asthma

ARS: Acute rhinosinusitis

CRS: Chronic rhinosinusitis

EPOS: European Position Paper on Rhinosinusitis and Polyps

FESS: Functional endoscopic sinus surgery

Flow: Nasal respiratory flow

Ig: Immunoglobulin

ISCS: Isotonic sodium chloride solution

MCT: Mucociliary clearing time

NAR: Nonallergic rhinitis

Pa: Pascal 
R: $\quad$ Resistance

RURT: Recurrent upper airway infections.

\section{Conflict of Interests}

Sarah Keller, Volker König, and Ralph Mösges report no conflict of interests concerning this paper.

\section{Authors' Contribution}

All authors have contributed to, seen, and approved the paper.

\section{Acknowledgment}

The authors would like to thank Marie-Josefine Joisten, M.A., for her editorial assistance.

\section{References}

[1] J. Bousquet, C. Bachert, G. W. Canonica et al., "Unmet needs in severe chronic upper airway disease (SCUAD)," Journal of Allergy and Clinical Immunology, vol. 124, no. 3, pp. 428-433, 2009.

[2] N. Bhattacharyya, "The economic burden and symptom manifestations of chronic rhinosinusitis," American Journal of Rhinology, vol. 17, no. 1, pp. 27-32, 2003.

[3] J. Bousquet, P. van Cauwenberge, and N. Khaltaev, "Allergic rhinitis and its impact on asthma," Journal of Allergy and Clinical Immunology, vol. 108, supplement 5, pp. S147-334, 2001.

[4] D. V. Wallace, M. S. Dykewicz, D. I. Bernstein et al., "The diagnosis and management of rhinitis: an updated practice parameter," Journal of Allergy and Clinical Immunology, vol. 122, supplement 2, pp. S1-S84, 2008.

[5] M. A. Sande and J. M. Gwaltney, "Acute community-acquired bacterial sinusitis: continuing challenges and current management," Clinical Infectious Diseases, vol. 39, supplement 3, pp. S151-S158, 2004.

[6] M. Thomas, B. Yawn, D. Price, V. Lund, J. Mullol, and W. Fokkens, "EPOS primary care guidelines: European Position Paper on the primary care diagnosis and management of Rhinosinusitis and Nasal Polyps 2007-a summary," Primary Care Respiratory Journal, vol. 17, no. 2, pp. 79-89, 2008.

[7] W. J. Fokkens, V. Lund, J. Mullol et al., "EPOS, 2012: European position paper on rhinosinusitis and nasal polyps 2012. A summary for otorhinolaryngologists," Rhinology, vol. 50, no. 1, pp. 1-12, 2012.

[8] D. Hastan, W. J. Fokkens, C. Bachert et al., "Chronic rhinosinusitis in Europe-an underestimated disease. A GA2LEN study," Allergy, vol. 66, no. 9, pp. 1216-1223, 2011.

[9] V. Benson and M. A. Marano, "Current estimates from the National Health Interview Survey, 1995," Vital and Health Statistics. Series 10, Data from the National Health Survey, no. 199, pp. 1-428, 1998.

[10] P. W. Hellings, W. J. Fokkens, C. Akdis et al., "Uncontrolled allergic rhinitis and chronic rhinosinusitis: where do we stand today?” Allergy, vol. 68, no. 1, pp. 1-7, 2013.

[11] D. Rabago and A. Zgierska, "Saline nasal irrigation for upper respiratory conditions," American Family Physician, vol. 80, no. 10, pp. 1117-1119, 2009.
[12] J. C. Kassel, D. King, and G. K. Spurling, "Saline nasal irrigation for acute upper respiratory tract infections," Cochrane Database of Systematic Reviews, no. 3, Article ID CD006821, 2010.

[13] R. Harvey, S. A. Hannan, L. Badia, and G. Scadding, "Nasal saline irrigations for the symptoms of chronic rhinosinusitis," Cochrane Database of Systematic Reviews, no. 3, Article ID CD006394, 2007.

[14] B. A. Stuck, C. Bachert, P. Federspil et al., "Rhinosinusitis guidelines-unabridged version: S2 guidelines from the German Society of Otorhinolaryngology, Head and Neck Surgery," HNO, vol. 60, no. 2, pp. 141-162, 2012.

[15] O. Kaschke, "Auswirkungen einer Steroidphobie in Deutschland auf die Therapie mit topischen Glukokortikoiden," MedReport, vol. 32, article 10, 2008.

[16] N. Achilles and R. Mösges, "Nasal saline irrigations for the symptoms of acute and chronic rhinosinusitis," Current Allergy and Asthma Reports, vol. 13, no. 2, pp. 229-235, 2013.

[17] R. E. Gliklich and R. Metson, "Economic implications of chronic sinusitis," Otolaryngology - Head and Neck Surgery, vol. 118, no. 3, part 1, pp. 344-349, 1998.

[18] M. S. Blaiss, "Allergic rhinitis: direct and indirect costs," Allergy and Asthma Proceedings, vol. 31, no. 5, pp. 375-380, 2010.

[19] K. E. Hermelingmeier, R. K. Weber, M. Hellmich, C. P. Heubach, and R. Mösges, "Nasal irrigation as an adjunctive treatment in allergic rhinitis: a systematic review and meta-analysis," American Journal of Rhinology and Allergy, vol. 26, no. 5, pp. el19-e125, 2012.

[20] G. Hildebrandt and C. Gutenbrunner, "Balneologie," in Handbuch der Balneologie und Medizinischen Klimatologie, pp. 187476, Springer, 1998.

[21] W. Fresenius and H. Kußmaul, "Einführung in Chemie und Charakteristik der Heilwässer un Peloide," in Die deutschen Kurorte und ihre natürlichen Heilmittel, Flöttmann, 2004, http://www.baederkalender.de/broschuere/11/Einfuehrung-inChemie-und-Charakteristik-der-Heilwaesser-und-Peloide.

[22] M. Costantino, E. Lampa, and G. Nappi, "Effectiveness of sulphur spa therapy with politzer in the treatment of rhinogenic deafness," Acta Otorhinolaryngologica Italica, vol. 26, no. 1, pp. 7-13, 2006.

[23] P. C. Braga, G. Sambataro, M. Dal Sasso, M. Culici, M. Alfieri, and G. Nappi, "Antioxidant effect of sulphurous thermal water on human neutrophil bursts: chemiluminescence evaluation," Respiration, vol. 75, no. 2, pp. 193-201, 2008.

[24] P. Deetjen, "Radon-Balneotherapie-neue Aspekte," Physikalische Medizin Rehabilitationsmedizin Kurortmedizin, vol. 2, no. 3, pp. 100-103, 2008.

[25] A. Salami, M. Dellepiane, B. Crippa et al., "Sulphurous water inhalations in the prophylaxis of recurrent upper respiratory tract infections," International Journal of Pediatric Otorhinolaryngology, vol. 72, no. 11, pp. 1717-1722, 2008.

[26] A. Salami, M. Dellepiane, F. Strinati, L. Guastini, and R. Mora, "Sulphurous thermal water inhalations in the treatment of chronic rhinosinusitis," Rhinology, vol. 48, no. 1, pp. 71-76, 2010.

[27] G. Ottaviano, G. Marioni, L. Giacomelli et al., "Smoking and chronic rhinitis: effects of nasal irrigations with sulfurousarsenical-ferruginous thermal water. A prospective, randomized, double-blind study," American Journal of OtolaryngologyHead and Neck Medicine and Surgery, vol. 33, no. 6, pp. 657-662, 2012.

[28] G. Ottaviano, G. Marioni, C. Staffieri et al., "Effects of sulfurous, salty, bromic, iodic thermal water nasal irrigations in 
nonallergic chronic rhinosinusitis: a prospective, randomized, double-blind, clinical, and cytological study," American Journal of Otolaryngology-Head and Neck Medicine and Surgery, vol. 32, no. 3, pp. 235-239, 2011.

[29] T. Marullo and A. Abramo, "Effects of one cycle of inhalation crenotherapy with radioactive fluoridated oligomineral," Acta Otorhinolaryngologica Italica, vol. 20, supplement 63, no. 4, pp. $1-13,2000$.

[30] M. Oremus, C. Wolfson, A. Perrault, L. Demers, F. Momoli, and Y. Moride, "Interrater reliability of the modified Jadad quality scale for systematic reviews of Alzheimer's disease drug trials," Dementia and Geriatric Cognitive Disorders, vol. 12, no. 3, pp. 232-236, 2001.

[31] K. Obtułowicz, J. Składzień, J. Michalak, J. Gawlik, and I. Wróblewska, "The efficacy of subterranean therapy in the salt chamber of Kinga Spa in Wieliczka for patients suffering from allergic rhinitis," Przeglad Lekarski, vol. 56, no. 12, pp. 760-762, 1999.

[32] M. Costantino, "The rhinogenic deafness and SPA therapy: clinical-experimental study," Clinica Terapeutica, vol. 159, no. 5, pp. 311-315, 2008.

[33] A. V. Pagliari, F. Klinger, V. Bandi, B. P. Banzatti, M. Rosmarini, and M. Klinger, "Efficacy of thermal sulphurous water after functional septo-rhinoplasty," Medicina Clinica e Termale, vol. 20, no. 64, pp. 21-23, 2008.

[34] G. Nappi, C. de Vita, M. M. Masciocchi, and S. de Luca, "A clinical study of the use of sulphurous water "Madonna Assunta" as a treatment of rhinogenous deafness," Medicina Clinica e Termale, vol. 12, no. 44-45, pp. 103-109, 1998.

[35] A. Varricchio, M. Giuliano, M. Capasso et al., "Salso-sulphide thermal water in the prevention of recurrent respiratory infections in children," International Journal of Immunopathology and Pharmacology, vol. 26, no. 4, pp. 941-952, 2013.

[36] D.-H. Kim and S. W. Yeo, "Effects of normal saline and selenium-enriched hot spring water on experimentally induced rhinosinusitis in rats," International Journal of Pediatric Otorhinolaryngology, vol. 77, no. 1, pp. 117-122, 2013.

[37] A. R. Jadad, R. A. Moore, D. Carroll et al., "Assessing the quality of reports of randomized clinical trials: is blinding necessary?" Controlled Clinical Trials, vol. 17, no. 1, pp. 1-12, 1996.

[38] G. Nappi, D. Passali, and S. de Luca, "A case-control study of the inhalatory therapy in nasal respiratory activity at Grotta Giusti Spa," Medicina Clinica e Termale, vol. 19, no. 61, pp. 74-78, 2006.

[39] D. Pagani, E. Galliera, G. Dogliotti et al., "Carbon dioxideenriched water inhalation in patients with allergic rhinitis and its relationship with nasal fluid cytokine/chemokine release," Archives of Medical Research, vol. 42, no. 4, pp. 329-333, 2011.

[40] D. Passali, M. Lauriello, G. C. Passali et al., "Clinical evaluation of the efficacy of Salsomaggiore (Italy) thermal water in the treatment of rhinosinusal pathologies," Clinica Terapeutica, vol. 159, no. 3, pp. 181-188, 2008.

[41] A. Vassallo, L. Califano, and G. Villari, "Clinical study on 40 cases of inflammatory pathologies of upper respiratory and digestive tract treated by inhalatory crenotherapy," Clinica Terapeutica, vol. 160, no. 1, pp. 17-20, 2009.

[42] M. Bregant, "Combined thermal-surgical therapeutic approach in vasomotor rhinitis," Medicina Clinica e Termale, vol. 19, no. 60, pp. 24-26, 2006.

[43] R. Jean, M. Fourot-Bauzon, and P. Perrin, "Cures thermales en pneumo-allergologie et en ORL pédiatriques," Expansion Scientifique Publications, vol. 39, no. 5, pp. 293-299, 1992.
[44] G. Fenu, A. Carai, A. C. Montella et al., "Effects of isotonic salso-bromo-iodine thermal water after sinunasal surgery: a preliminary morphological study," Journal of Alternative and Complementary Medicine, vol. 16, no. 4, pp. 341-343, 2010.

[45] T. Marullo and A. Abramo, "Effects of sulphur-arsenic-ferrous water treatment on specific chronic phloglosis of the upper respiratory tract," Acta Otorhinolaryngologica Italica, vol. 19, supplement 61, no. 4, pp. 5-14, 1999.

[46] M. Costantino, G. Nappi, S. de Luca, F. Rossi, and E. Lampa, "Efficacy of inhalation crenotherapy with oligomineral radioactive water on ORL: clinic-experimental study," Medicina Clinica e Termale, vol. 13, no. 47, pp. 211-219, 2001.

[47] E. de Nobili and V. G. Tiepolo, "Comparative evaluation of efficacy of crenotherapeutic Politzer with sulphurous water versus crenotherapeutic Politzer and autoinsufflation (Otovent) in patients with tubaric dysfunction and secretory otitis media," Medicina Clinica e Termale, vol. 20, no. 64, pp. 30-34, 2008.

[48] S. Ragusa, G. Caruso, and T. Bensi, "Efficacy of sulphurous Spa therapy on inflammatory chronic disease of VADS," Medicina Clinica e Termale, vol. 14, no. 50-51, pp. 377-387, 2002.

[49] M. Costantino, F. Rossi, and E. Lampa, "Inhalant therapy with sulphur water in ORL: clinical-experimental study," Clinica Terapeutica, vol. 154, no. 6, pp. 395-400, 2003.

[50] G. Nappi, I. G. Carrubba, and S. de Luca, "Spa therapy influence on nasal mucociliary transport in patients with rhinosinusitis," Medicina Clinica e Termale, vol. 14, no. 49, pp. 305-313, 2002.

[51] L. Pollastrini, G. Cristalli, and A. Abramo, "The treatment of a chronic inflammation of the upper respiratory airways by inhalation thermal therapy with sulfur-sulfate-bicarbonatealkaline-earth metal water: rhinomanometric study and the study of the mucociliary transport," Acta Otorhinolaryngologica Italica, vol. 16, supplement 55, no. 6, pp. 85-90, 1996.

[52] G. Cristalli, A. Abramo, and L. Pollastrini, "Treatment of chronic inflammation of the upper respiratory airways by inhalation thermal therapy with sulfur-sulfate-bicarbonatecarbonate-alkaline earth mineral water: a study of nasal cytology," Acta Otorhinolaryngologica Italica, vol. 16, supplement 55, no. 6, pp. 91-94, 1996.

[53] S. De Luca, D. Antonaci, and G. Nappi, "Efficacy of inhalatory Spa therapy for upper respiratory tract pathologies with sulphurous water of Tabiano Spa in Hospital far from Spa Centre," Medicina Clinica e Termale, vol. 19, no. 62-63, pp. 107-115, 2006.

[54] A. Staffieri, C. Miani, A. M. Bergamin, P. Arcangeli, and P. Canzi, "Effect of sulfur salt-bromine-iodine thermal waters on albumin and IgA concentrations in nasal secretions," Acta Otorhinolaryngologica Italica, vol. 18, no. 4, pp. 233-238, 1998.

[55] A. Staffieri and A. Abramo, "Sulphurous-arsenical-ferruginous (thermal) water inhalations reduce nasal respiratory resistance and improve mucociliary clearance in patients with chronic sinonasal disease: preliminary outcomes," Acta OtoLaryngologica, vol. 127, no. 6, pp. 613-617, 2007.

[56] A. Staffieri, F. Marino, C. Staffieri et al., "The effects of sulfurousarsenical-ferruginous thermal water nasal irrigation in wound healing after functional endoscopic sinus surgery for chronic rhinosinusitis: a prospective randomized study, American Journal of Otolaryngology-Head and Neck Medicine and Surgery, vol. 29, no. 4, pp. 223-229, 2008.

[57] A. Passariello, M. di Costanzo, G. Terrin et al., "Crenotherapy modulates the expression of proinflammatory cytokines and immunoregulatory peptides in nasal secretions of children with chronic rhinosinusitis," American Journal of Rhinology and Allergy, vol. 26, no. 1, pp. e15-e19, 2012. 
[58] D. Passali, E. de Corso, S. Platzgummer et al., "Spa therapy of upper respiratory tract inflammations," European Archives of Oto-Rhino-Laryngology-Head Neck Surg, vol. 270, no. 2, pp. 565-570, 2013.

[59] F. M. Passali, A. Crisanti, G. C. Passali et al., "Efficacy of inhalation therapy with water of Salsomaggiore (Italy) in chronic and recurrent nasosinusal inflammation treatment," Clinica Terapeutica, vol. 159, no. 3, pp. 175-180, 2008.

[60] M. Miraglia del Giudice, F. Decimo, N. Maiello et al., "Effectiveness of ischia thermal water nasal aerosol in children with seasonal allergic rhinitis: a randomized and controlled study," International Journal of Immunopathology and Pharmacology, vol. 24, no. 4, pp. 1103-1109, 2011.

[61] D. Moher, A. Liberati, J. Tetzlaff, and D. G. Altman, "Preferred reporting items for systematic reviews and meta-analyses: the PRISMA statement," Annals of Internal Medicine, vol. 151, no. 4, pp. 264-269, W64, 2009.

[62] V. J. Lund and I. S. Mackay, "Staging in rhinosinusitus," Rhinology, vol. 31, no. 4, pp. 183-184, 1993.

[63] A. Timmer and B. Richter, "Systematische Übersichtsarbeiten zu Fragen der Therapie und Prävention. Teil 3-Wie werden die Ergebnisse zusammengefasst und dargestellt?" Arzenimitteltherapie, vol. 26, no. 10, pp. 299-303, 2008.

[64] J. W. Georgitis, "Nasal hyperthermia and simple irrigation for perennial rhinitis: changes in inflammatory mediators," Chest, vol. 106, no. 5, pp. 1487-1492, 1994.

[65] O. Michel, "Nasal irritation in case of rhinosinusitis," LaryngoRhino-Otologie, vol. 85, no. 6, pp. 448-460, 2006.

[66] G. M. Corbo, A. Foresi, P. Bonfitto, A. Mugnano, N. Agabiti, and P. J. Cole, "Measurement of nasal mucociliary clearance," Archives of Disease in Childhood, vol. 64, no. 4, pp. 546-550, 1989.

[67] P. W. Hellings, G. Scadding, I. Alobid et al., "Executive summary of European Task Force document on diagnostic tools in rhinology," Rhinology, vol. 50, no. 4, pp. 339-352, 2012.

[68] B. Thiagarajan, "Nasal resistance its importance and measurement," ENT Scholar, vol. 1, no. 3, 2012.

[69] R. Jankowski, M. Persoons, B. Foliguet, L. Coffinet, C. Thomas, and B. Verient-Montaut, "Eosinophil count in nasal secretions of subjects with or without nasal symptoms," Rhinology, vol. 38, no. 1, pp. 23-32, 2000.

[70] S. K. Wise, C. N. Ahn, D. M. R. Lathers, R. M. Mulligan, and R. J. Schlosser, "Antigen-specific IgE in sinus mucosa of allergic fungal rhinosinusitis patients," American Journal of Rhinology, vol. 22, no. 5, pp. 451-456, 2008.

[71] H. Garn and H. Renz, "Epidemiological and immunological evidence for the hygiene hypothesis," Immunobiology, vol. 212, no. 6, pp. 441-452, 2007.

[72] L. Bellussi, J. Cambi, and D. Passali, "Functional maturation of nasal mucosa: role of secretory immunoglobulin A (SIgA)," Multidisciplinary Respiratory Medicine, vol. 8, no. 1, article 46, 2013.

[73] Y. Kurono, G. Mogi, and T. Fujiyoshi, "Secretory IgA and bacterial adherence to nasal mucosal cells," Annals of Otology, Rhinology and Laryngology, vol. 98, no. 4, part 1, pp. 273-277, 1989. 


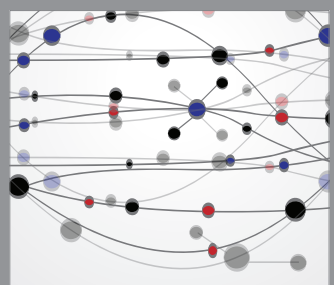

The Scientific World Journal
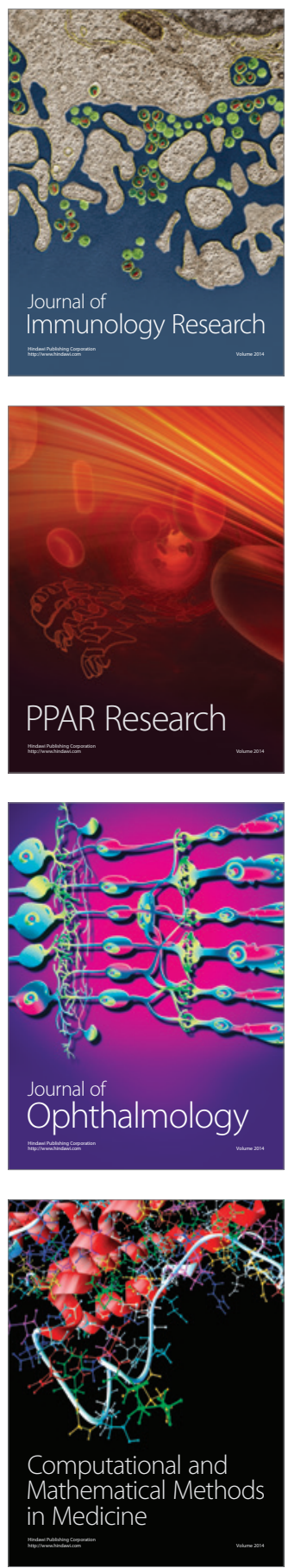

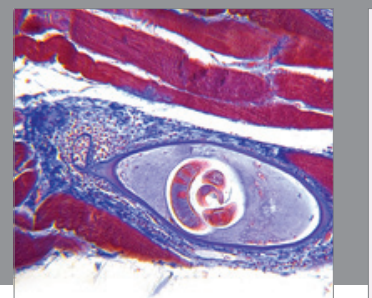

Gastroenterology

Research and Practice
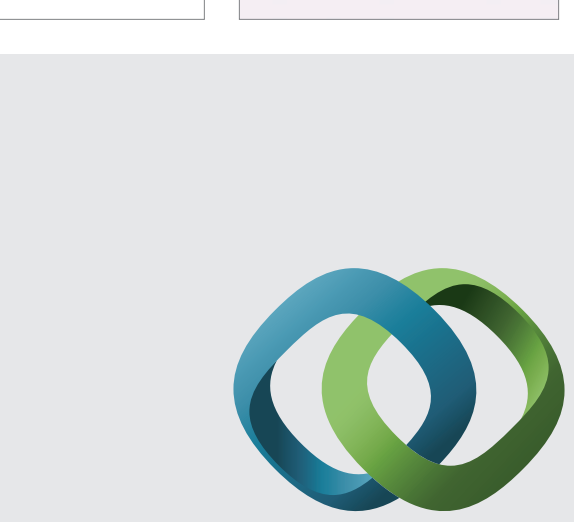

\section{Hindawi}

Submit your manuscripts at

http://www.hindawi.com
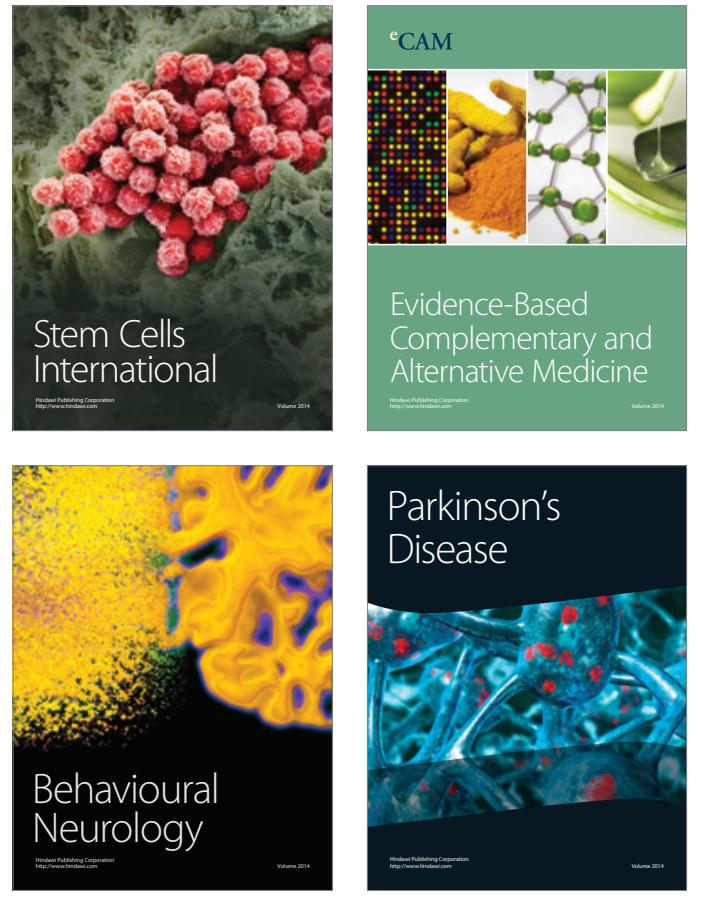
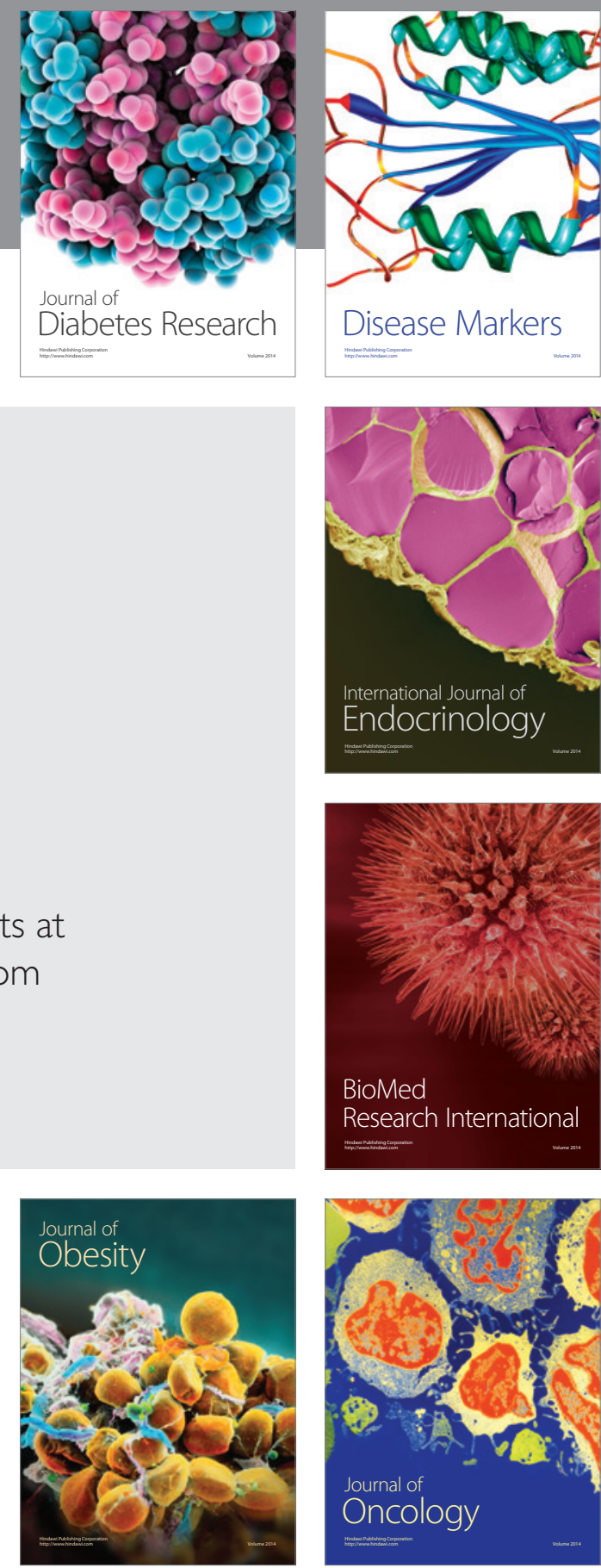

Disease Markers
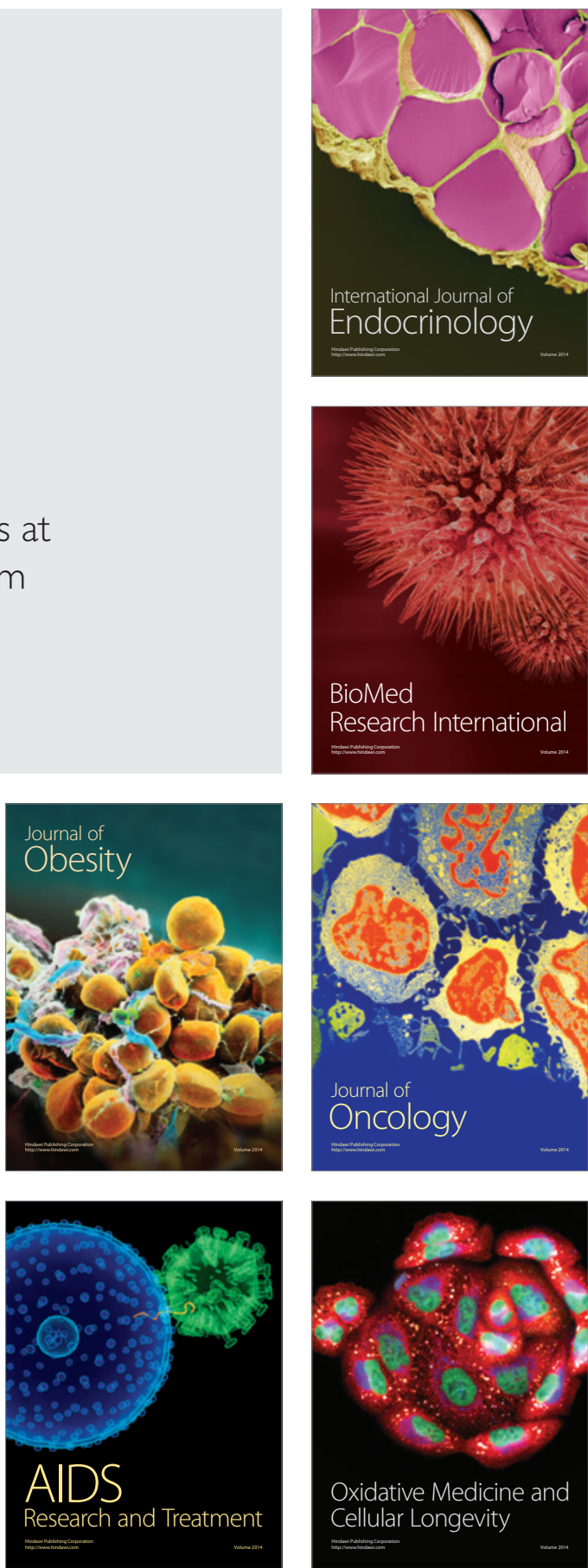